\title{
logurte elaborado à base de leite de búfala sabor queijo com geleia de goiaba
}

Yogurt produced with buffalo milk flavoured with cheese and guava jelly

Autores | Authors

*Daniela Helena Pelegrine GUIMARÃES

Universidade de São Paulo (USP) Escola de Engenharia de Lorena (ELL) Departamento de Engenharia Química Estrada do Campinho, s/n CEP: $12.602-810$ Lorena/SP - Brasil email:dhguima@usp.br

Fernanda Reis de Souza Rodrigues e SILVA Nathalia Machado LÊNTHOLA

Universidade de Taubaté (UNITAU) Departamento de Ciências Agrárias Curso de Engenharia de Alimentos Taubaté/SP - Brasil email: fernandarsrsilva@hotmail.com nathy_lentola@hotmail.com

*Autor Correspondente / Corresponding Author

Recebido: Ago. 04, 2014

Aprovado: Mar. 13, 2015

\section{Resumo}

O presente trabalho teve como objetivo verificar a aplicabilidade do leite de búfala no desenvolvimento de iogurte. O iogurte foi preparado utilizando os seguintes ingredientes: leite de búfala padronizado, leite de vaca, água filtrada e cultura lática. Os leites foram misturados em proporções de $0 \%$ de leite de búfala $(F I), 50 \%$ de leite de búfala (FII), 30\% de leite de búfala (FIII), 70\% de leite de búfala (FIV) e 100\% de leite de búfala (FV). O produto foi submetido a testes sensoriais de aceitação quanto aos atributos cor, textura, aroma e sabor. Com relação aos resultados da análise sensorial, a formulação com $70 \%$ de leite de búfala apresentou características organolépticas estatisticamente similares à formulação com 100\% de leite de vaca. Sendo assim, a formulação FIII foi utilizada no desenvolvimento do iogurte com sabor queijo acrescido da geleia de goiaba, o qual foi submetido a testes sensoriais de aceitação, cujos resultados mostraram-se satisfatórios, indicando boa aceitação do produto.

Palavras-chave: Laticínios; Leite bubalino; Análise sensorial.

\section{Summary}

The following work aims to verify the applicability of buffalo milk in the development of yogurt. Yogurt was prepared using the following ingredients: buffalo milk, cow's milk, filtered water and a lactic culture. The milk samples were mixed in the proportions of $100 \%$ cow's milk ( $F I), 50 \%$ of buffalo's milk and $50 \%$ cow's milk (FII); $30 \%$ of buffalo's milk and $70 \%$ cow's milk (FIII), $70 \%$ of buffalo's milk and $30 \%$ cow's milk (FIV) and 100\% of buffalo's milk (FV). The product was submitted to a sensory acceptance evaluation for the attributes of colour, texture, aroma and taste. Regarding the results of the sensory analysis, the formulation with $70 \%$ of buffalo milk presented organoleptic characteristics statistically similar to the formulation with $100 \%$ of cow's milk. Therefore, FIII was used in the development of yogurt flavoured with cheese and guava jelly, which was subjected to sensory acceptance tests, the results of which were satisfactory, indicating good product acceptance.

Key words: Yogurt; Buffalo milk; Sensory analysis. 


\section{Introdução}

A bubalinocultura tem aumentado de forma bastante significativa a participação no cenário agropecuário brasileiro, principalmente para produção leiteira, devido ao elevado teor de sólidos totais do leite, essencialmente a gordura (BORGES et al., 2009). Embora seja uma alternativa tecnológica viável, o leite bubalino apresenta características organolépticas indesejáveis quando consumido integralmente. Esse quadro se reverte quando há padronização da gordura para $2 \%$ a 3\% (BUZI et al., 2009; LOURENÇO JUNIOR e GARCIA, 2008; FAO, 2013).

A industrialização do leite e derivados surge como uma necessidade para a maioria dos produtores no Brasil pela falta de opção para comercializá-lo in natura e pela possibilidade de maior faturamento bruto mensal, por agregar um valor maior ao leite produzido (GUERRA et al., 2005; RODRIGUES et al., 2008).

Nos últimos 5 anos, a produção e procura do leite de búfala e seus derivados vêm aumentando e ganhando uma grande importância no Brasil (BORGES et al., 2009). Esse leite apresenta algumas peculiaridades em comparação ao leite bovino, destacando-se o sabor adocicado, devido ao elevado extrato seco, evidenciado pelo maior teor de lactose (DALMASSO et al., 2011). Outras características o diferem do leite de vaca: a concentração de colesterol, que é menor; a quantidade de calorias, que é maior; e a relação do teor de alguns minerais, tais como cálcio e magnésio, que estão ricamente presentes nesse leite. A quantidade de aminoácidos também é um fator diferencial, pois sua quantidade é maior no leite de búfala do que no leite de vaca (CZERWENKA et al., 2010).

O leite de búfala é muito utilizado na fabricação de queijos e cada tipo requer uma técnica de produção específica, sendo que quando processados a partir do leite de búfala geralmente apresentam maior rendimento (NERES et al., 2012; VIEIRA et al., 2011). Além dos queijos, também se produzem outros lácteos com o leite bubalino, como iogurte, doce de leite e mesmo sorvete. Dentre esses produtos, o iogurte ocupa posição de destaque, pois, além de amenizar o problema de perecibilidade do leite (cujo estado líquido e composição nutritiva o tornam propenso a degradação microbiana), apresenta elevado valor nutricional e grande aceitabilidade, tanto por crianças quanto por adultos. O iogurte constitui excelente fonte de vitaminas do complexo B, vitaminas e minerais, ajudando na manutenção do corpo, no desenvolvimento de ossos e dentes fortes e saudáveis e na transformação dos carboidratos, gorduras e proteínas em energia e na formação e reparação dos tecidos corporais (CUNHA NETO et al., 2005; CUNHA et al., 2008; NOBRE et al., 2006; MATHIAS et al., 2013).
No Brasil, de acordo com Moraes e Bollini (2010), o consumo per capita do iogurte aumentou em mais de 100\% em 20 anos; segundo os autores, esse aumento no consumo está associado às mudanças nos hábitos alimentares nos domicílios brasileiros.

\section{Material e métodos}

O presente trabalho trata das formulações de iogurte a partir do leite de búfala e de vaca em diferentes proporções.

Inicialmente os leites de búfala e de vaca foram avaliados por meio de análises físico-químicas, tais como pH (IAL, 1985 - N. 4.7.1), densidade (AOAC, 1980 - 16196), acidez titulável (IAL, 1985 - N.4.7.2), teores de gordura (BLIGH e DYER, 1959) e proteína (AOAC, 1980 - 38012).

A seguir, os leites bubalino e bovino passaram, separadamente, por um processo de pasteurização em trocador de calor de tubo duplo, segundo o esquema seguido por Pelegrine et al. (2007). Posteriormente, o iogurte foi então elaborado, de acordo com a seguinte formulação: leite de búfala, leite de vaca, açúcar e cultura lática própria para iogurte (marca Bio Rich, contendo bifidobactérias e lactobacilos vivos). No presente trabalho, cinco formulações de iogurte foram desenvolvidas, sendo elas: $0 \%$ de leite de búfala e $100 \%$ de leite de vaca $(\mathrm{FI})$, $50 \%$ de leite de búfala $+50 \%$ de leite de vaca (FII), $30 \%$ de leite de búfala $+70 \%$ de leite de vaca (FIII), $70 \%$ de leite de búfala $+30 \%$ de leite de vaca (FIV) e $100 \%$ de leite de búfala (FV).

Primeiramente foi pesado o leite, sendo ele a seguir transferido para um béquer, onde foi aquecido em banho termostático até $43{ }^{\circ} \mathrm{C}$. Uma vez atingida a temperatura de $43^{\circ} \mathrm{C}$, a cultura lática foi acrescentada, na proporção de $1,5 \%(\mathrm{~m} / \mathrm{v})$ e, em seguida, a mistura foi homogeneizada durante 2 minutos. Passados 30 minutos, a temperatura do banho foi ajustada para $40^{\circ} \mathrm{C}$. Ao se observar a formação do coágulo firme, sem a liberação de soro, o aquecimento foi interrompido, sendo marcado o tempo de incubação (cerca de 60 minutos para todas as formulações), assim como a acidez final do produto recém-fabricado. A cada formulação adicionou-se açúcar na proporção de $5 \%$ da massa total e aromatizante sabor frutas vermelhas na proporção de $1 \%$ da massa total, conforme indicado na legislação (BRASIL, 2000). O iogurte foi então embalado em recipientes com tampa e estocado a frio numa temperatura de $2^{\circ} \mathrm{C}$ a $4^{\circ} \mathrm{C}$, para sua maior conservação. As diferentes formulações de iogurte foram avaliadas com relação aos teores de gordura (BLIGH e DYER, 1959) e proteína (AOAC, 1980 - 38012). Antes de as formulações serem submetidas aos testes sensoriais, o projeto de pesquisa foi submetido ao Comitê de Ética em Pesquisa da Universidade de Taubaté 
(Protocolo 274/09), sendo aprovado, de acordo com a Declaração 209/2009).

Foram realizados testes sensoriais de aceitação e intenção de compra do produto por uma equipe não treinada de 30 julgadores. Os atributos aparência, cor, sabor, textura e impressão global foram avaliados por teste afetivo por meio de uma escala hedônica de nove pontos, conforme Uliana et al. (2012). As amostras foram servidas em porções de $15 \mathrm{~g}$, em copos descartáveis brancos codificados com algarismos de três dígitos aleatórios; a ordem de apresentação foi balanceada.

Cada provador recebeu juntamente com as amostras de iogurte uma ficha de avaliação que continha 9 categorias (ou pontos) correspondentes, respectivamente, a: 9 , gostei extremamente; 8 , gostei muito; 7, gostei moderadamente; 6, gostei ligeiramente; 5 , não gostei nem desgostei; 4, desgostei ligeiramente; 3 , desgostei moderadamente; 2, desgostei muito; e 1 , desgostei extremamente.

Os resultados da análise sensorial foram submetidos a análise de variância (Anova) e as médias comparadas pelo teste de Tukey ao nível $5 \%$. A formulação mais aceita foi então utilizada no desenvolvimento do iogurte com sabor de queijo acrescido da geleia de goiaba, cujo procedimento foi semelhante ao anteriormente descrito. Mas, ao se observar a formação do coágulo firme, sem a liberação de soro, o aquecimento foi interrompido e o queijo ralado foi adicionado, numa proporção de $10 \%$ da massa do iogurte. Antes de o iogurte ser embalado, foi adicionada a geleia de goiaba na proporção de $10 \%$ da massa total do iogurte, o qual foi então estocado a frio numa temperatura de $2{ }^{\circ} \mathrm{C}$ a $4^{\circ} \mathrm{C}$ para sua maior conservação.

Para o preparo da geleia de goiaba utilizou-se polpa de goiaba, açúcar e pectina ATM, sendo o pH da mistura ajustado na faixa de 3,0 a 3,4 (ideal para a geleificação) com o uso do acidulante ácido cítrico; a cocção foi realizada em tacho de aço inoxidável com agitação contínua.

O iogurte sabor queijo com geleia de goiaba foi então submetido a testes sensoriais de aceitabilidade, conforme anteriormente descrito, além do teste de intenção de compra, o qual conteve 5 faces, correspondendo, respectivamente a: 5 , certamente compraria; 4 , possivelmente compraria; 3 , talvez compraria/não compraria; 2, possivelmente não compraria; e 1 , certamente não compraria.

\section{Resultados e discussão}

\subsection{Caracterização dos produtos}

A caracterização físico-química dos leites de vaca e de búfala, assim como das diferentes formulações do iogurte, é apresentada na Tabela 1.

Da tabela anterior verifica-se que o teor médio de gordura e de proteína do leite de búfala foram superiores aos do leite vaca em $121 \%$ e $67,7 \%$, respectivamente. Esses resultados estão de acordo com as observações feitas por Wong et al. (1996). Por outro lado, tais resultados são inferiores aos obtidos por Verruma e Salgado (1994); uma explicação para esse fato é que, além dos fatores genéticos, a composição do leite é influenciada por fatores ambientais, estágio de lactação, ordem de lactação, prática de ordenha, clima, nutrição e incidência de doenças (NERES et al., 2012).

Os teores de acidez e de proteína, assim como o valor do $\mathrm{pH}$, foram muito semelhantes nas cinco formulações do iogurte elaboradas com leite bovino e bubalino $(p>0,05)$. O percentual de gordura variou de acordo com a padronização, ou seja, os valores foram similares aos respectivos teores no leite utilizado como matéria-prima, visto que menores teores foram obtidos quando o leite de vaca foi utilizado em maiores proporções, o que condiz com os resultados obtidos por Cunha Neto et al. (2005).

O resultado da avaliação sensorial é apresentado na Tabela 2 onde, nas amostras que mostraram-se significativamente diferentes das demais, as notas estão acompanhadas por sobrescritos diferentes das que não apresentaram diferenças, para cada atributo. Sendo assim, pode-se notar que para as características cor, sabor e textura não houve diferença estatística entre as formulações I, II, III e IV. Para a característica aparência, as formulações I, III e IV apresentaram melhores avaliações e foram estatisticamente iguais.

Ainda com relação aos resultados apresentados na Tabela 2, observa-se que até $70 \%$ de leite de búfala

Tabela 1. Determinação das propriedades físicas e químicas das amostras de leite e das formulações de iogurte.

\begin{tabular}{cccccccc} 
Produto & $\begin{array}{c}\text { Leite de } \\
\text { vaca }\end{array}$ & $\begin{array}{c}\text { Leite de } \\
\text { búfala }\end{array}$ & FI & FII & FIII & FIV & FV \\
\hline pH & $6,82(0,020)$ & $6,89(0,013)$ & $5,31(0,021)$ & $5,35(0,046)$ & $5,28(0,032)$ & $4,80(0,026)$ & $5,01(0,000)$ \\
Acidez $(\%)$ & $1,78(0,110)$ & $1,81(0,098)$ & $0,54(0,033)$ & $0,52(0,004)$ & $0,53(0,003)$ & $0,59(0,010)$ & $0,68(0,017)$ \\
Densidade $(\mathrm{g} / \mathrm{mL})$ & $1,027(0,083)$ & $1,035(0,056)$ & -- & -- & -- & -- & -- \\
Teor de gordura $(\%)$ & $2,71(0,203)$ & $5,99(0,172)$ & $3,33(0,165)$ & $3,40(0,207)$ & $4,66(0,129)$ & $5,32(0,095)$ & $5,88(0,108)$ \\
Teor proteico $(\%)$ & $2,29(0,0731)$ & $3,84(0,094)$ & $2,79(0,304)$ & $2,61(0,159)$ & $2,98(0,234)$ & $3,18(0,127)$ & $3,71(0,241)$ \\
\hline
\end{tabular}

FI - 100\% de leite de vaca; FII - 50\% de leite de búfala e 50\% de leite de vaca; FIII - 70\% de leite de búfala e 30\% de leite de vaca; FIV - 70\% de leite de vaca e $30 \%$ de leite de búfala; e FV - $100 \%$ de leite de búfala. 
logurte elaborado à base de leite de búfala sabor queijo com geleia de goiaba

GUIMARÃES, D. H. P. et al.

Tabela 2. Análise de variância e teste de Tukey das características sensoriais nas diferentes formulações elaboradas a partir do leite de búfala.

\begin{tabular}{cccccc}
$\begin{array}{c}\text { Características } \\
\text { organolépticas }\end{array}$ & FI & FII & FIII & FIV & FV \\
\hline Cor & $5,7^{\mathrm{a}}(0,374)$ & $4,27^{\mathrm{a}}(0,264)$ & $4,87^{\mathrm{a}}(0,853)$ & $4,83^{\mathrm{a}}(0,825)$ & $3,63^{\mathrm{b}}(0,392)$ \\
Aparência & $6,17^{\mathrm{a}}(0,592)$ & $4,23^{\mathrm{b}}(0,362)$ & $4,90^{\mathrm{a}}(0,426)$ & $5,37^{\mathrm{a}}(0,362)$ & $3,46^{\mathrm{b}}(0,636)$ \\
Sabor & $6,27^{\mathrm{a}}(0,954)$ & $4,53^{\mathrm{a}}(0,490)$ & $4,83^{\mathrm{a}}(0,527)$ & $5,17^{\mathrm{a}}(0,517)$ & $3,23^{\mathrm{b}}(1,052)$ \\
Textura & $6,30^{\mathrm{a}}(0,152)$ & $4,40^{\mathrm{a}}(0,377)$ & $4,97^{\mathrm{a}}(0,378)$ & $5,23^{\mathrm{a}}(0,468)$ & $3,40^{\mathrm{b}}(0,356)$ \\
\hline
\end{tabular}

a: amostra não apresentou diferença significativa da formulação padrão. b: amostra apresentou diferença significativa da formulação padrão.

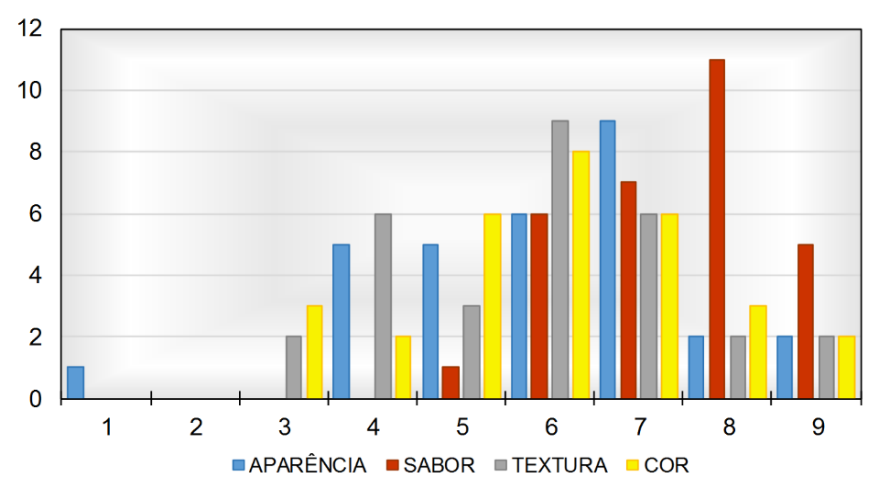

Figura 1. Histograma referente ao teste de aceitação do iogurte sabor queijo com geleia de goiaba a partir de uma mistura composta por leite de vaca (30\%) e de búfala (70\%).

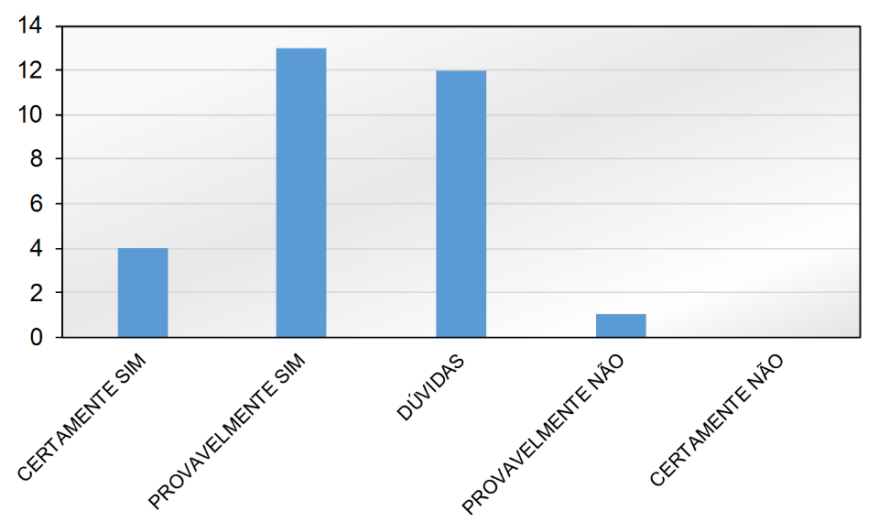

Figura 2. Histograma referente à intenção de compra do iogurte sabor queijo com geleia de goiaba a partir de uma mistura composta por leite de vaca (30\%) e de búfala (70\%).

na mistura (FIV) resultou em características sensoriais estatisticamente iguais às do leite de vaca. Sendo assim, a formulação FIV foi a escolhida para ser utilizada no desenvolvimento do iogurte com sabor de queijo acrescido de geleia de goiaba, já que esta formulação resultou em teores proteico e de gordura mais elevados e, estatisticamente, não diferiu da formulação FI com relação aos atributos sensoriais.

O iogurte com sabor de queijo acrescido da geleia de goiaba foi então submetido a testes sensoriais de aceitação, cujos resultados encontram-se nas Figuras 1 e 2.
Na Figura 1, o eixo das abcissas refere-se ao conceito atribuído pelo provador e o eixo das ordenadas, ao número de provadores que atribuíram determinado conceito.

Pelos resultados das Figuras 1 e 2 observa-se que o produto apresentou aceitabilidade satisfatória, visto que em todos os gráficos as notas convergem para o lado esquerdo, indicando boa aceitação.

\section{Conclusão}

Dos resultados obtidos e apresentados nos itens anteriores pode-se notar a viabilidade de se utilizar o leite de búfala no enriquecimento do iogurte, uma vez que a formulação do produto contendo $70 \%$ de leite de búfala apresentou características sensoriais similares ao produto elaborado de maneira tradicional (ou seja, com $100 \%$ de leite de vaca).

No presente trabalho também nota-se que o iogurte elaborado a partir do leite de búfala sabor queijo com geleia de goiaba apresenta aceitabilidade satisfatória, demonstrando a viabilidade no desenvolvimento desse novo tipo de produto.

\section{Agradecimentos}

Ao Conselho Nacional de Desenvolvimento Científico e Tecnológico (CNPq).

\section{Referências}

AOAC INTERNATIONAL - AOAC. Official methods of analysis. Washington: Sidney Willians, 1980. 1141 p.

BLIGH, E. G.; DYER, W. J. A rapid method of total lipid extraction and purification. Canadian Journal of Biochemistry and Physiology, Ottawa, v. 37, n. 8, p. 911-917, 1959. http://dx.doi. org/10.1139/059-099. PMid:13671378

BORGES, K. C.; MEDEIROS, A. C. L.; CORREIA, R. T. P. Iogurte de leite de búfala sabor cajá: caracterização físico-química e aceitação sensorial entre indivíduos de 11 a 16 anos. Alimentos e Nutrição, Marília, v. 20, n. 2, p. 295-300, 2009.

BRASIL. Ministério da Saúde. Agência Nacional de Vigilância Sanitária - ANVISA. Resolução RDC n 79, de 28 de agosto de 2000. Diário Oficial da União, Basília, DF, 31 ago. 2000. 
logurte elaborado à base de leite de búfala sabor queijo com geleia de goiaba

GUIMARÃES, D. H. P. et al.

Disponível em: <http://www.anvisa.gov.br/cosmeticos/guia/ html/79_2000.pdf>. Acesso em: 18 ago. 2014.

BUZI, K. A.; PINTO, J. P. A. N.; RAMOS, P. R. R.; BIONDI, G. F. Análise microbiológica e caracterização eletroforética do queijo mussarela elaborado a partir de leite de búfala. Ciência e Tecnologia de Alimentos, Campinas, v. 29, n. 1, p. 7-11, 2009. http://dx.doi.org/10.1590/S0101-20612009000100002.

CUNHA NETO, O. C.; OLIVEIRA, C. F.; HOTTA, R. M.; SOBRAL, P. J. A. Avaliação físico-química e sensorial do iogurte natural produzido com leite de búfala contendo diferentes níveis de gordura. Ciência e Tecnologia de Alimentos, Campinas, v. 25, n. 3, p. 448-453, 2005. http://dx.doi.org/10.1590/S010120612005000300010.

CUNHA, T. M.; CASTRO, F. P.; BARRETO, P. L. M.; BENEDET, H. D.; PRUDÊNCIO, E. S. Avaliação físico-química, microbiológica e reológica de bebida láctea e leite fermentado adicionados de probióticos. Semina. Ciências Agrárias, Londrina, v. 29, n. 1 , p. 103-116, 2008.

CZERWENKA, C.; MULLER, L.; LINDNER, W. Detection of the adulteration of water buffalo milk and mozzarella with cow's milk by liquid chromatography-mass spectrometry analysis of b-lactoglobulin variants. Food Chemistry, Londres, v. 122, n. 3, p. 901-908, 2010. http://dx.doi.org/10.1016/j. foodchem.2010.03.034.

DALMASSO, A.; CIVERA, T.; LA NEVE, F.; BOtTERO, M. T. Simultaneous detection of cow and buffalo milk in mozzarella cheese by Real-Time PCR assay. Food Chemistry, Londres, v. 124, n. 1, p. 362-366, 2011. http://dx.doi.org/10.1016/j. foodchem.2010.06.017.

FOOD AND AGRICULTURE ORGANIZATION - FAO. FAO statistical yearbook 2013. Rome: $F A O, 2013.289 p$.

GUERRA, R. B.; NEVES, E. C. A.; PENA, R. S. Caracterização e processamento de leite bubalino em pó em secador por nebulização. Ciência e Tecnologia de Alimentos, Campinas, v. 25 , n. 3, p. 443-447, 2005. http://dx.doi.org/10.1590/S010120612005000300009

INSTITUTO ADOLFO LUTZ - IAL. Normas analíticas do Instituto Adolfo Lutz. São Paulo: IAL, 1985. 531 p.

LOURENÇO JUNIOR, J. B.; GARCIA, A. R. Panorama da bubalinocultura na Amazônia. In: ENCONTRO INTERNACIONAL DA PECUÁRIA DA AMAZÔNIA, 1., 2008, Belém, Anais... Belém: FAEPA; Instituto Frutal; SEBRAE-PA, 2008. Disponível em: <http://www.alice.cnptia.embrapa.br/alice/bitstream/ doc/409969/1/LOURENCO2008AmazonpecPanorama.pdf> Acesso em: 20 agosto 2013.
MATHIAS, T. R. S.; ANDRADE, K. C. S.; ROSA, C. L. S.; SILVA, B. A. Avaliação do comportamento reológico de diferentes iogurtes comerciais. Brazilian Journal of Food Technology, Campinas, v. 16, n. 1, p. 12-20, 2013. http://dx.doi.org/10.1590/ S1981-67232013005000004.

MORAES, P. C. B. T.; BOLLINI, H. M. A. Perfil sensorial de iogurtes comerciais sabor morango nas versões tradicional e light. Brazilian Journal of Food Technology, Campinas, v. 13, n. 2, p. 112-119, 2010. http://dx.doi.org/10.4260/ BJFT2010130200015.

NERES, L. S.; LOURENÇO JUNIOR, J. B.; PACHECO, E. A.; MONTEIRO, R. C. R.; SATO, S. T. A.; LIMA, S. C. G.; GARCIA, A. R.; NAHUM, B. S. logurte de leite de búfala saborizado com manga (Mangifera indica L.): aceitação sensorial e custo de produção. Agroecossistemas, v. 4, n. 2, p. 79-84, 2012.

NOBRE, L. N. N.; BRESSAN, J.; SOBRINHO, P. S. C.; COSTA, N. M. B.; MININ, V. P. R.; CECON, P. R. Volume de iogurte light e sensações subjetivas do apetite de homens eutróficos e com excesso de peso. Revista Nutrição, Campinas, v. 19, n. 5, p. 591-600, 2006.

PELEGRINE, D. H. G.; GOMES, M. T. M. S.; OLIVEIRA, K. F. Whey protein fouling in a tubular heat exchanger: effect of milk temperature and Reynolds number. In: HEAT EXCHANGER FOULING AND CLEANING, 7., 2007, Tomar. Anais... Tomar: Institute of Thermodinamics and Thermal Engineering, University of Stuttgart, 2007. p. 11-18.

RODRIGUES, C. F. C.; IAPICHINI, J. E. C. B.; LISERRE, A. M.; SOUZA, C. B.; FACHINI, C.; REICHERT, R. H. Oportunidades e desafios da bubalinocultura familiar da região sudoeste paulista. Revista Tecnologia \& Inovação Agropecuária, São Paulo, v. 1, p. 100-109, 2008.

ULIANA, M. R.; VENTURINI FILHO, W. G.; ULIANA, L. R. Teste de aceitação de bebida mista de soja e amora. Brazilian Journal of Food Technology, Campinas, v. 15, n. 2, p. 174-181, 2012. http://dx.doi.org/10.1590/S1981-67232012005000002.

VERRUMA, M. R.; SALGADO, J. M. Análise química do leite de búfala em comparação ao leite de vaca. Science Agricultural, v. 51, p. 131-137, 1994.

VIEIRA, R. G.; FALCÃO FILHO, R. S.; DUARTE, T. F.; PESSOA, T. R. B.; QUEIROGA, R. C. R. E.; MOREIRA, R. T. Acceptability and sensory preference of cheese curds elaborated with female buffalo, goat and cow milk. Revista do Instituto da Laticínios Cândido Tostes, Juiz de Fora, v. 363, n. 63, p. 12-16, 2011.

WONG, D. W. S.; CAMIRAND, W. M.; PAVLATH, A. E. Structures and functionalities of milk proteins. Critical Reviews in Food Science and Nutrition, Boca Raton, v. 36, n. 8, p. 807-844, 1996. 